\title{
Regulation and Improvement of Cellulase Production: Recent Advances
}

\author{
Nasir Ali1 ${ }^{*}$, Muhammad Ammar Athar1, Yasir Hayat Khan1, Muhammad Idrees², \\ Dawood Ahmad ${ }^{3}$ \\ ${ }^{1}$ School of Life Science, Xiamen University, Xiamen, China \\ ${ }^{2}$ Chengdu Institute of Biology, Chinese Academy of Sciences, Chengdu, China \\ ${ }^{3}$ Institute of Biotechnology and Genetic Engineering, Khyber Pakhtunkhwa Agricultural University, Peshawar, \\ Pakistan \\ Email: ${ }^{*}$ nasir.biotech@yahoo.com
}

Received 13 August 2014; revised 21 September 2014; accepted 1 October 2014

Copyright (C) 2014 by authors and Scientific Research Publishing Inc.

This work is licensed under the Creative Commons Attribution International License (CC BY). http://creativecommons.org/licenses/by/4.0/

cC) (i) Open Access

\begin{abstract}
Cellulases and hemicellulases are the main industrial sources from different microorganisms used to depolymerise plant biomass to simple sugars that are converted to chemical intermediates and biofuels, such as ethanol. Cellulases are formed adaptively, and several positive (xyr1, Ace2, HAP2/3/5) and negative (Ace1, Cre1) components involved in this regulation are now known. In this review, we summarise current knowledge about how cellulase biosynthesis is regulated, and outline recent approaches and suitable strategies for facilitating the targeted improvement of cellulase production by genetic engineering. Trichoderma reesei is the preferred organism for producing industrial cellulases. However, a more efficient heterologous expression system for enzymes from different organism is needed to further improve its cellulase mixture. In addition those optimizations of the promoter and linker for hybrid genes can dramatically improve the efficiency of heterologous expression of cellulase genes.
\end{abstract}

\section{Keywords}

Cellulase, Regulation, Transcription, Promoter, Review

\section{Introduction}

Lignocellulosic materials are widely considered important sources for the production of sugar streams that can be fermented to ethanol and other organic chemicals [1]. The chemical composition of poplar wood is characterized by its high polysaccharide content (approximately $80 \%$ holocellulose, made up of 50\% cellulose and 30\%

\footnotetext{
"Corresponding author.
} 
hemicelluloses) and low lignin content (about 20\% or less), making it an attractive biomass for fermentable sugar production [2]. The enzymatic hydrolysis of the cellulosic materials has extensively been studied in the last few decades in order to obtain more soluble sugars [3]. The most widely investigated source of cellulase is Trichoderma reesei [4]. However, the T. reesei cellulase system has a deficient b-glucosidase (BGL) activity, which leads to the incomplete hydrolysis of cellobiose, causing serious inhibition of the enzymes [5]. This problem can be overcome by the addition of extra BGL, e.g. from Aspergillus niger [6]. Research has focused on the optimization of the hydrolysis process and the enhancement of the cellulase activity in order to improve the yield and rate of the enzymatic hydrolysis [7].

Plant biomass is the most abundant renewable bioresource on Earth, and is considered to play the same role in coming times. The main constituents of the plant biomass is cellulose and lignocelluloses which further could be converted into sugar and other carbohydrates and then might be transferred into ethanol and other several useful biochemicals [8]. The major enzyme responsible for the conversion of cellulose and lignocellulosic biomass into simple sugars is Cellulase. It is an important industrial enzyme and finds applications in several industrial processes [9]. Cellulase is a multi-enzyme complex of three different enzymes: exoglucanase-/Cellobiohydrolases (CBH), endoglucanase (EG) and beta-glucosidase (BGL) which acts synergistically for complete hydrolysis of cellulose. Cellulose fibers are firstly cleaved by endoglucanase releasing small cellulose fragments with free-reducing and non-reducing ends which are attacked by exoglucanase to release small oligosaccharides, cellobiose, and are finally hydrolysed into glucose monomers by beta-glucosidase. Beta-glucosidase completes the final step of hydrolysis by converting the cellobiose (an intermediate product of cellulose hydrolysis) to glucose [10].

Cellulase can be regulated with three types of stimulants regarding medium, factor affecting medium and transcriptional basis. Cellulase production can be positively regulated by using cellulose as a medium while negatively regulated by using glucose and cellobiose media. On transcriptional basis, Cellulase can be enhanced by positive regulatory factor $x y r$, Ace2 and HAP2/3/5 complexes while repressed by negative regulatory factor Cre1 and Ace1 (Figure 1). Enhanced mutant strains have been reported to produce over $35 \mathrm{~g} /$ liter extracellular protein [11], and nearly all of the secreted protein consists of cellulases and hemicellulases [12]. The synergistic activities of cellobiohydrolases (CBHs1), endoglucanases (EGs), and $b$-glucosidases are necessary for the efficient hydrolysis of cellulose. The hemicellulolytic system of Trichoderma consists of a more complex set of enzymes among which are the two endo-b-xylanases, the $b$-mannanase, and the side chain cleaving enzymes. The production of the main cellulases in Trichoderma is regulated at the transcriptional level depending on the carbon source available [13], the genes being repressed tightly by glucose and induced up to several thousand folds by cellulose or the disaccharide sophorose [14]. Carbon catabolite repression of Cellulase genes has been extensively studied, and the repressor gene Cre1 of Trichoderma has been shown to mediate glucose repression of cellulase expression [15]. In the various conditions, studied expression of the main Cellulase genes, $c b h 1, c b h 2$, egl1, and egl2, has been shown to be coordinate, and expression of the $c b h 1$ gene encoding cellobiohydrolase has been shown to be always the strongest [16]. Analysis of relative expression levels of various Cellulase genes on different carbon sources and inducing compounds indicate that several regulatory mechanisms operate, some of which may be shared by genes encoding cellulases and hemicellulases [17]. However, little information is available on the molecular mechanism involved in the strong activation of the Cellulase genes.

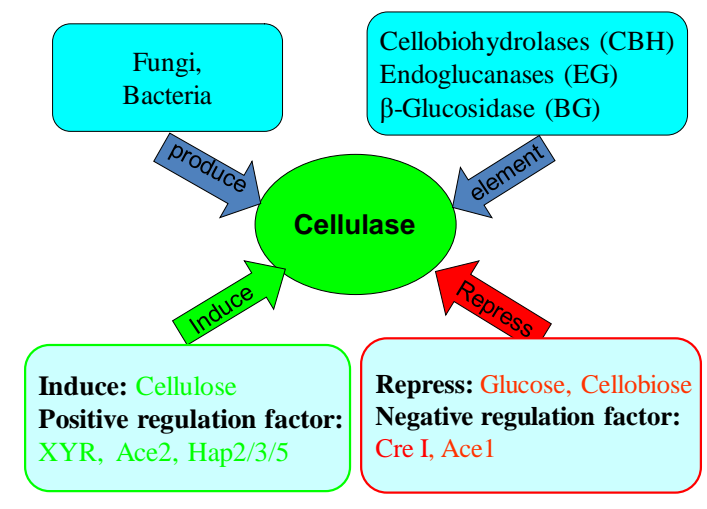

Figure 1. A sketch of regulatory factors of cellulase. 


\section{Hyper Expression System by $c b h 1$ Promoter}

The promoter $c b h 1$ known to be a strong inducible promoter, and is therefore commonly used to construct highefficient heterologous expression vectors in some fungi [18]. However, three putative carbon catabolite repressor binding sites are present in the region from -685 to -724 nt of the $c b h 1$ promoter (Figure 2). They are considered to reduce transcripts of $c b h 1$ when glucose is present in the fermentation medium [19] [20]. The deletion of these repressor binding sites and introduction of multi-copy activator binding sites in $c b h 1$ promoter not only eliminated the glucose repression effect, but also increased promoter activity and production levels of heterologous proteins. Expression of $c b h 1$ is dramatically decreased when repressor CreI is bound to its promoter, especially in culture media containing glucose. The deletion of the three CreI binding sites and the repetition of multi-copy regions with activator binding sites resulted in an increase of cbh1 promoter efficiency and thus a higher expression level of heterologous proteins. However, the $c b h 1$ promoter is repressed by glucose and negatively regulated by CreI/CreA [21].

\section{Glucose Antirepression Promoter ProA}

A novel endogenous glucose antirepression promoter proA from aspartic protease protein encoding the gene, proA were obtained by genome walking technology in filamentous fungi Hypocrea orientalis EU7-22 which could highly express under both induction and glucose repression condition for cellulase production. This promoter has high activity with the $\beta$-glucosidase (Bgl1) enzyme from the same species of Hypocrea orientalis Eu7-22. In comparison with the receipt strain EU7-22, the positive transformant (Bgl-2) for cellulase production, filter paper activity and $\beta$-glucosidase activity increased by $10.8 \%$ and $18.2 \%$, respectively. When $2 \%$ glucose supplemented into the cellulose inducer medium, the filter paper activity and $\beta$-glucosidase activity promoted by $18.3 \%$ and 52.0\%, respectively. The results showed proA promoter successfully drove Bgl1 gene over-expression in $\mathrm{H}$. orientalis and the cellulase activity upgrade. It indicated that the proA promoter has a certain antiglucose repressor effect [22].

\section{Xylanase Promoter}

It is a zinc binuclear cluster protein binding to a GGCTAA-motif arranged as an inverted repeat, is the general main activator of cellulase and hemicellulase gene expression. Deletion of xyr1 eliminates cellulase induction on cellulose and sophorose, indicates that's it proving its essential role in the induction process. Whether an in-

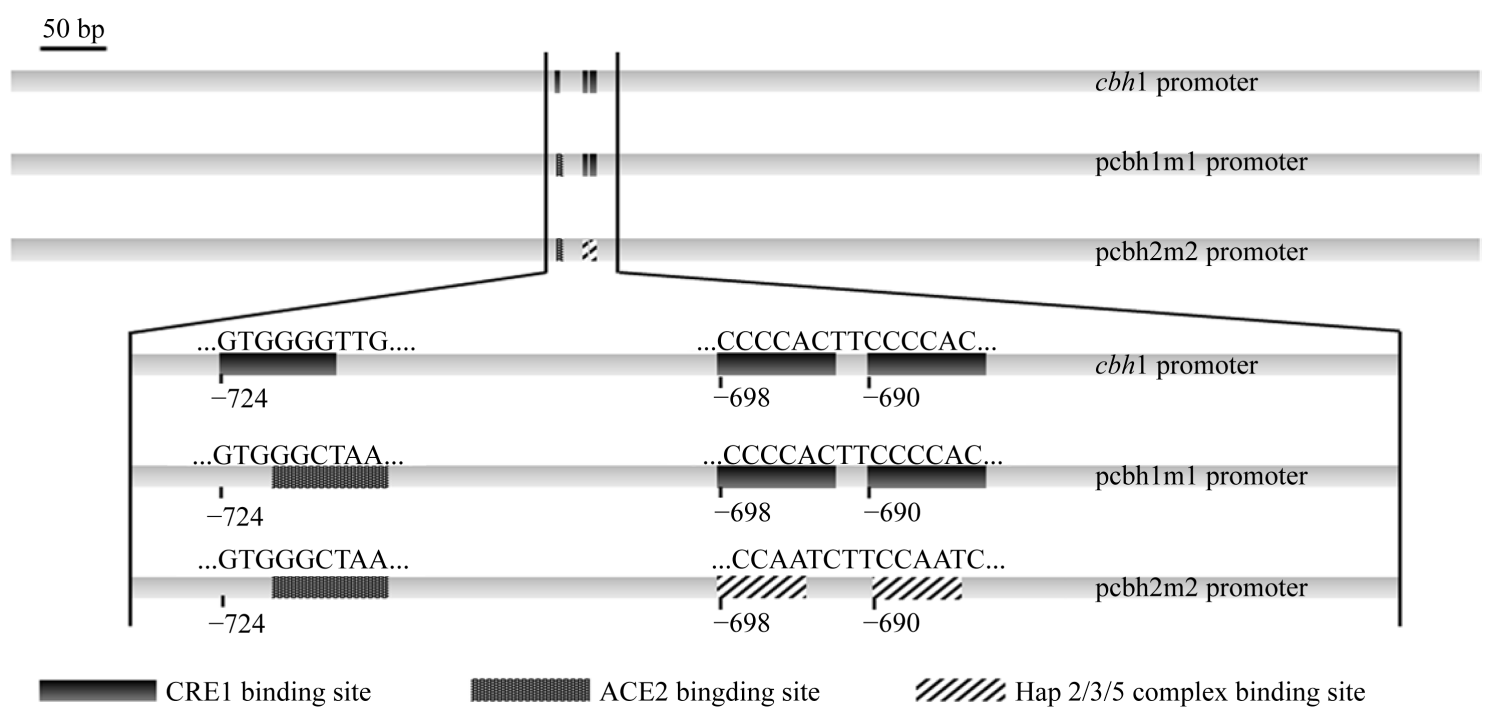

Figure 2. Schematic structure of $c b h 1$ promoter and its mutants. There are three CreI binding sites located at -690 , -698 and -724 in wild type cbh 1 promoter. An ACEII binding site was replaced the CreI binding site at -724 in promoter pcbh1m1. Based on pcbh1m1, HAP2/3/5 complex binding sites were substituted for the remaining two CreI binding sites in promoter pcbh1m2. 
crease in constitutive expression of xyr 1 would increase enzyme formation is not sufficiently understood. Fusion of $x y r 1$ gene under the regulatory signals of the nag1 ( $\mathrm{N}$-acetyl- $\beta$-D-glucosaminidase) promoter, which resulted in a slightly earlier beginning of xylanase formation but did not significantly enhance the final enzyme titre [23]. Using promoter deletion analysis, we could previously prove that a 217-bp fragment of the xyn1 5_noncoding region bears all information necessary for transcriptional regulation of xyn1 gene expression. Furthermore, we could demonstrate that a tight carbon catabolite repression of xyn 1 expression is mediated by Cre 1 via binding to two "SYGGRG" consensus sequences arranged as an inverted repeat in the xyn1 promoter. Additionally, some evidence for the involvement of a CCAAT box in transcriptional regulation of xyn 1 was given by Zeilinger and coworkers. So far, no further cis-acting elements and trans-acting factors of this system have been characterized. In Aspergillus niger, the xylanolytic system is mainly under control of the GAL4-type transcriptional regulator XlnR which, presumably, is a wide domain regulator governing the expression of more than 10 genes involved not only in the degradation of xylan but also in xylose metabolism and cellulose degradation. Lately, the isolation of two transcription factors, Ace1 and Ace2, both being involved in the cellulase expression of Trichoderma reesei, was reported. While Ace2 affects regulation of transcription of the xyn2 gene, Ace1 was reported as a partial repressor of cellulase and xylanase expression.

\section{Transcriptional Regulation of Cellulase Gene Expression}

Most of the cellulase genes are regulated in a consistent way, although the relative ratio of their expression is somewhat different in higher producer mutants [24], probably due to promoter titration effects. The identification of genes involved in transcriptional regulation of cellulase gene expression has been a major effort in the past 10 years. Today, three positive transcriptional activators (xyr1, Ace2 and the HAP2/3/5 complex) as well as two repressors (AceI and the carbon catabolite repressor Cre1) have been demonstrated to be involved in this regulation. AceI gene encoding the novel cellulase regulator isolated under the promoter of the main cellulase gene, $c b h 1$. Ace1 contains three Cys2His2-type zinc fingers and was shown to bind in vitro to eight sites containing the core sequence 5'-AGGCA scattered along the 1.15-kb cel7a promoter [25]. Deletion of Ace1 resulted in an increase in the expression of all the main cellulase genes and two xylanase genes in sophorose- and cellulose-induced cultures, indicating that AceI acts as a repressor of cellulase and xylanase expression.

The second characterised cellulase activator Ace2 also encodes for a protein belonging to the class of zinc binuclear cluster proteins found exclusively in fungi [26]. It has so far been shown to occur only in Trichoderma spp. During growth on cellulose, deletion of the Ace2 gene led to lowered induction kinetics of cellulase mRNAs and 30\% to $70 \%$ reduced cellulase activity [27]. Interestingly, cellulase induction by sophorose was not affected by Ace2 deletion. The DNA-binding domain of Ace2 was shown to bind in vitro to the 5'-GGCTAATAA site present in the $c b h 1$ promoter. Therefore, both $x y r$ and Ace2 are able to bind the complete motif, suggested that phosphorylation as well as dimerisation is prerequisites for binding Ace2 to its target promoter.

\section{Carbon Catabolite Repression}

Expression of a large majority of the cellulase genes that have been studied in $H$. jecorina and other filamentous fungi does not occur during growth on glucose. This has been shown to be due to both inducer exclusion (that is, inhibition of inducer [sophorose] uptake by D-glucose [28] and glucose repression [29] [30]. The latter specifies a transcriptional regulation controlling the preferential use of substrates such as D-glucose or other monosaccharides whose catabolism provides a high yield of ATP and is more generally called carbon catabolite repression (CCR). Consequently, one of the earliest attempts for engineering cellulase production was removal of carbon catabolite repression. Classical mutagenesis combined with selection for 2-desoxyglucose resistance (an agent believed primarily to enrich carbon catabolite-resistant mutants [31]) has led to increased cellulase producers such as H. jecorina RUT C30 [32], RL-P37 [33] and CL847 [34]), thus supporting the possible importance of CCR in cellulase formation. However, later molecular genetic analyses showed that $T$. reesei is generally less affected by CCR than, for example, Aspergillus and that the cellulase and xylanase genes are mainly affected at their low constitutive level, their induction being only partially affected, and consequently these mutants did not form much cellulase on D-glucose (see below). In Trichoderma/Hypocrea and other ascomycetous fungi, the key player in this glucose repression is the Cys2His2 type transcription factor CreI/CreA [35] [36]. In addition to CreA, A. nidulans is known to contain three further genes, $\mathrm{CreB}$, $\mathrm{CreC}$ and creD, which participate in CCR [37] [38]. Respective orthologues are also present in the H. jecorina genome. 
CreB encodes a deubiquitinating enzyme and is a functional member of a novel subfamily of the $u b p$ family defined by the human homologue UBH1 [39]. It forms a complex with a WD40-repeat protein encoded by CreC [40], which is required to prevent the proteolysis of CreB in the absence of CCR. Disruption of the creB homologue Cre2 in $H$. jecorina led to deregulation of genes normally subject to CCR. Interestingly, the E3 ubiquitin ligase LIM1 also responds to cellulase inducing conditions and binds to the $c b h 2$-promotor. Mutations in CreD suppress the phenotypic effects of mutations in CreC and CreB [41]. CreD contains arrestin domains and PY motifs and is highly similar to Saccharomyces cerevisiae Rod1p and Rog3p, which interact with the ubiquitin ligase Rsp5p [42]. Deubiquitinating enzymes are cysteine proteases, and the most common role for ubiquitin is to target proteins for degradation by the proteasome. Recently, the activation domains of certain transcription factors have been demonstrated to serve as direct targets for ubiquitylation, and it has been hypothesized that modulation of activation domains by the ubiquitylation level provides an important mechanism for the regulation of gene transcription [43]. It is tempting to speculate that this explanation may extend to catabolite repression in H. jecorina.

The way in which the presence of glucose triggers CCR is still only poorly understood in filamentous fungi. In S. cerevisiae, the D-glucose and D-fructose phosphorylating enzymes are also involved in D-glucose and carbon catabolite sensing: it has three hexose-6-phosphorylating enzymes including two hexokinases and one glucokinase. Each of them enables $S$. cerevisiae to grow on D-glucose, but the hexokinase Hxk2p is responsible for the main enzymatic activity and glucose repression mediated by the carbon catabolite repressor Mig1p (whose DNA-binding domain is highly similar to that of Cre1) [44] [45]. The mechanism by which Hxk2p contributes to glucose repression has not yet been fully elucidated, but its catalytic activity seems to be dispensable and thus signal transmission may rather depend on substrate bindinginduced conformational changes in the Hxk2p protein or a direct regulatory role of the Hxk2p in the nucleus [46]. In A. nidulans only a single glucokinase and a single hexokinase are present. It is showed that only mutations in both kinase genes lead to CreAmediated carbon catabolite derepression [47].

Filamentous fungus Trichoderma reesei is one of the most efficient cellulase producers and has a long history in producing hydrolytic enzymes. Several mutant strains can produce cellulases $(40 \mathrm{~g} / \mathrm{L})$ and the major cellulase, cellobiohydrolase I (CBH I), accounts for approximately $50 \%$ of all secreted proteins. Thus, $c b h 1$ promoter has been considered the strongest promoter in $T$. reesei.

\section{Conclusion}

Our knowledge of how cellulase formation is regulated has considerably advanced throughout the last 10 years, and the recently released genome sequence of $H$. jecorina. In addition, the current understanding of the process, as outlined in this review, will form a useful framework for genomic and transcriptomic analyses of various cellulase over-producing mutants, as currently performed in several laboratories worldwide. The next step will be the discovery of the regulatory processes altered during mutant isolation. It is also likely that such studies will identify additional cellular levels, bottlenecks and regulatory loops for cellulase formation in H. jecorina which have not yet been dealt with.

\section{Acknowledgements}

This work was supported by the National Natural Science Foundation of China (Grant No. 31170067, No. 21303142), the research fund of Fujian Provincial Natural Science Foundation (Grant No: 2012J05029), the National Basic Research Program of China (973 Program, Grant No. 2010CB732201) and the Ministry of Agriculture of China (948 program, 2013-Z70).

\section{References}

[1] Cardona, C.A. and Sanchez, C.J. (2007) Fuel Ethanol Production: Process Design Trends and Integration Opportunities. Bioresource Technology, 98, 2415-2457. http://dx.doi.org/10.1016/j.biortech.2007.01.002

[2] Balatinecz, J.J. and Kretschmann, D.E. (2001) Properties and Utilization of Poplar Wood. NRC, Research Press National Research, Council of Canada, ON KIA OR6, Canada, 277-291.

[3] Mooney, C.A., Mansfield, S.D., Touhy, M.G. and Saddler, J.N. (1998) The Effect of Initial Pore Volume and Lignin Content on the Enzymatic Hydrolysis of Softwoods. Bioresource Technology, 64, 113-119.

http://dx.doi.org/10.1016/S0960-8524(97)00181-8 
[4] Wilkins, M.R., Widmer, W.W., Grohmann, K. and Cameron, R.G. (2007) Hydrolysis of Grapefruit Peel Waste with Cellulase and Pectinase Enzymes. Bioresource Technology, 98, 1596-1601. http://dx.doi.org/10.1016/j.biortech.2006.06.022

[5] Persson, I., Tjerneld, F. and Hahn-Hagerdal, B.B. (1991) Fungal Cellulolytic Enzyme Production: A Review. Process Biochemistry, 26, 65-74. http://dx.doi.org/10.1016/0032-9592(91)80019-L

[6] Wright, J.D., Power, A.J. and Douglas, L.J. (1986) Design and Parameter Evaluation of an Enzymatic Hydrolysis Process (Separation Hydrolysis and Fermentation). Biotechnology and Bioengineering, 17, 285-302.

[7] Ferreira, S., Duarte, A.P., Ribeiro, M.H.L., Queiroz, J.A. and Domingues, F.C. (2009) Response Surface Optimization of Enzymatic Hydrolysis of Cistus ladanifer and Cytisus striatus for Bioethanol Production. Biochemical Engineering Journal, 45, 192-200. http://dx.doi.org/10.1016/j.bej.2009.03.012

[8] Lynd, L.R., et al. (2002) Microbial Cellulose Utilization: Fundamentals and Biotechnology. Microbiology and Molecular Biology Reviews, 66, 506-577. http://dx.doi.org/10.1128/MMBR.66.3.506-577.2002

[9] Esterbauer, H., Steiner, W., Labudova, I., Hermann, A. and Hayn, M. (1991) Production of Trichoderma Cellulase in Laboratory and Pilot Plant. Bioresource Technology, 36, 67-76. http://dx.doi.org/10.1016/0960-8524(91)90099-6

[10] Gadgil, N.J., Daginawala, H.F., Chakarabarti, T. and Khanna, P. (1995) Enhanced Cellulase Production by a Mutant of Trichoderma reesei. Enzyme and Microbial Technology, 17, 942-946. http://dx.doi.org/10.1016/0141-0229(94)00131-A

[11] Singhania, R.R., Patel, A.K., Sukumaran, R.K., Larroche, C. and Pandey, A. (2012) Role and Significance of $\beta$-Glucosidases in the Hydrolysis of Cellulose for Bioethanol Production. Bioresource Technology, 127, 500-507.

[12] Gritzali, M. and Brown, R.D.J. (1979) The Cellulase System of Trichoderma Relationships between Purified Extracellular Enzymes from Induced or Cellulose-Grown Cells. Advances in Chemistry, 181, 237-260. http://dx.doi.org/10.1021/ba-1979-0181.ch012

[13] Kubicek, C.P. and Penttilä, M. (1998) Regulation of Production of Plant Polysaccharide Degrading Enzymes by Trichoderma. In: Harman, G.E. and Kubicek, C.P., Eds., Trichoderma and Gliocladium, Taylor \& Francis Ltd., London.

[14] Mandels, M., Parrish, F.W. and Reese, E.T. (1962) Sophorose as an Inducer of Cellulase in Trichoderma viride. Journal of Bacteriology, 83, 400-408.

[15] Ilmén, M., Thrane, C. and Penttilä, M. (1996) The Glucose Repressor Genecre1 of Trichoderma: Isolation and Expression of a Full-Length and a Truncated Mutant Form. Molecular Genetics and Genomics, 251, 451-460.

[16] Ilmén, M., Saloheimo, A., Onnela, M.L. and Penttilä, M.E. (1997) Regulation of Cellulase Gene Expression in the Filamentous Fungus Trichoderma ressei. Applied and Environmental Microbiology, 63, 1298-1306.

[17] Margolles-Clark, M., Ilmén, M. and Penttilä, M. (1997) Expression Patterns of Ten Hemicellulase Genes of the Filamentous Fungus Trichoderma reesei on Various Carbon Sources. Journal of Biotechnology, 57, 167-179. http://dx.doi.org/10.1016/S0168-1656(97)00097-7

[18] Bower, B.S., Larenas, E.A. and Mitchinson, C. (2005) Exo-Endo Cellulase Fusion Protein. WO Patent No. WO2005093073.

[19] Nyyssönen, E. and Keränen, S. (1995) Multiple Roles of the Cellulase CBHI in Enhancing Production of Fusion Antibodies by the Filamentous Fungus Trichoderma reesei. Current Genetics, 28, 71-79. http://dx.doi.org/10.1007/BF00311884

[20] Ilmén, M., Onnela, M.L., Klemsdal, S., Keränen, S. and Penttilä, M. (1996) Functional Analysis of the Cellobiohydrolase I Promoter of the Filamentous Fungus Trichoderma reesei. Molecular Genetics and Genomics, 253, 303-314.

[21] Wohlers, I., Stachelscheid, H., Borstlap, J., Zeilinger, K. and Gerlach, J.C. (2009) The Characterization Tool: A Knowledge-Based Stem Cell, Differentiated Cell, and Tissue Database with a Web-Based Analysis Front-End. Stem Cell Research, 3, 88-95. http://dx.doi.org/10.1016/j.scr.2009.05.001

[22] Long, C., Cheng, Y., Gan, L., Liu, J. and Long, M. (2013) Identification of a Genomic Region Containing a Novel Promoter Resistant to Glucose Repression and Over-Expression of $\beta$-Glucosidase Gene in Hypocrea orientalis EU7-22. International Journal of Molecular Sciences, 14, 8479-8490. http://dx.doi.org/10.3390/ijms14048479

[23] Kubicek, C.P., Mikus, M., Schuster, A., Schmoll, M. and Seiboth, B. (2009) Metabolic Engineering Strategies for the Improvement of Cellulase Production by Hypocrea jecorina. Biotechnology for Biofuels, 2, 19. http://dx.doi.org/10.1186/1754-6834-2-19

[24] Foreman, P.K., Brown, D., Dankmeyer, L., Dean, R., Diener, S., Dunn-Coleman, N.S., Goedegebuur, F., Houfek, T.D., England, G.J., Kelley, A.S., Meerman, H.J., Mitchell, T., Mitchinson, C., Olivares, H.A., Teunissen, P.J., Yao, J. and Ward, M. (2003) Transcriptional Regulation of Biomass-Degrading Enzymes in the Filamentous Fungus Trichoderma reesei. The Journal of Biological Chemistry, 278, 31988-31997. http://dx.doi.org/10.1074/jbc.M304750200

[25] Saloheimo, A., Aro, N., Ilmén, M. and Penttilä, M. (2000) Isolation of the Ace1 Gene Encoding a Cys(2)-His(2) Tran- 
scription Factor Involved in Regulation of Activity of the Cellulase Promoter cbh1 of Trichoderma reesei. The Journal of Biological Chemistry, 275, 5817-5825. http://dx.doi.org/10.1074/jbc.275.8.5817

[26] Aro, N., Saloheimo, A., Ilmén, M. and Penttilä, M. (2001) ACEII, a Novel Transcriptional Activator Involved in Regulation of Cellulase and Xylanase Genes of Trichoderma reesei. The Journal of Biological Chemistry, 276, 2430924314. http://dx.doi.org/10.1074/jbc.M003624200

[27] Stricker, A.R., Trefflinger, P., Aro, N., Penttilä, M. and Mach, R.L. (2008) Role of Ace2 (Activator of Cellulases 2) within the xyn2 Transcriptosome of Hypocrea jecorina. Fungal Genetics and Biology, 45, 436-445. http://dx.doi.org/10.1016/j.fgb.2007.08.005

[28] Kubicek, C.P., Messner, R., Gruber, F., Mandels, M. and Kubicek-Pranz, E.M. (1993) Triggering of Cellulase Biosynthesis in Trichoderma reesei: Involvement of a Constitutive, Sophorose-Inducible, Glucoseinhibited $\beta$-Diglucoside Permease. The Journal of Biological Chemistry, 268, 19364-19368.

[29] Zeilinger, S., Schmoll, M., Pail, M., Mach, R.L. and Kubicek, C.P. (2003) Nucleosome Transactions on the Hypocrea jecorina (Trichoderma reesei) Cellulase Promoter cbh2 Associated with Cellulase Induction. Molecular Genetics and Genomics, 270, 46-55. http://dx.doi.org/10.1007/s00438-003-0895-2

[30] Ilmén, M., Onnela, M.L., Klemsdal, S., Keränen, S. and Penttilä, M. (1996) Functional Analysis of the Cellobiohydrolase I Promoter of the Filamentous Fungus Trichoderma reesei. Molecular Genetics and Genomics, 253, 303-314.

[31] Zimmermann, F.K. and Scheel, I. (1977) Mutants of Saccharomyces cerevisiae Resistant to Carbon Catabolite Repression. Molecular Genetics and Genomics, 154, 75-82. http://dx.doi.org/10.1007/BF00265579

[32] Eveleigh, D.E. and Montenecourt, B.S. (1979) Increasing Yields of Extracellular Enzymes. Advances in Applied Microbiology, 25, 57-74. http://dx.doi.org/10.1016/S0065-2164(08)70146-1

[33] Sheir-Neiss, G. and Montenecourt, B.S. (1984) Characterization of the Secreted Cellulases of Trichoderma reesei Wild Type Mutants during Controlled Fermentations. Applied Microbiology and Biotechnology, 20, 46-53. http://dx.doi.org/10.1007/BF00254645

[34] Durand, H., Clanet, H. and Tiraby, G. (1988) Genetic Improvement of Trichoderma reesei for Large Scale Cellulase Production. Enzyme and Microbial Technology, 10, 341-346. http://dx.doi.org/10.1016/0141-0229(88)90012-9

[35] Ilmén, M., Thrane, C. and Penttilä, M. (1996) The Glucose Repressor Gene Cre1 of Trichoderma: Isolation and Expression of a Full-Length and a Truncated Mutant Form. Molecular Genetics and Genomics, 251, 451-460.

[36] Dowzer, C.E. and Kelly, J.M. (1991) Analysis of the CreA Gene, a Regulator of Carbon Catabolite Repression in Aspergillus nidulans. Molecular and Cellular Biology, 11, 5701-5709.

[37] Todd, R.B., Lockington, R.A. and Kelly, J.M. (2000) The Aspergillus nidulans CreC Gene Involved in Carbon Catabolite Repression Encodes a WD40 Repeat Protein. Molecular Genetics and Genomics, 263, 561-570. http://dx.doi.org/10.1007/s004380051202

[38] Antonella A., Simona G and Vincenza F. (2007) Trichoderma reesei Homologue of Aspergillus nidualns CreB. Fungal Genetics Newsletter, 54, 98.

[39] Lockington, R.A. and Kelly, J.M. (2001) Carbon Catabolite Repression in Aspergillus nidulans Involves Deubiquitination. Molecular Microbiology, 40, 1311-1321. http://dx.doi.org/10.1046/j.1365-2958.2001.02474.x

[40] Lockington, R.A. and Kelly, J.M. (2002) The WD40-Repeat Protein CreC Interacts with and Stabilizes the Deubiquitinating Enzyme CreB in Vivo in Aspergillus nidulans. Molecular Microbiology, 43, 1173-1182. http://dx.doi.org/10.1046/j.1365-2958.2002.02811.x

[41] Boase, N.A. and Kelly, J.M. (2004) A Role for CreD, a Carbon Catabolite Repression Gene from Aspergillus nidulans, in Ubiquitination. Molecular Microbiology, 53, 929-940. http://dx.doi.org/10.1111/j.1365-2958.2004.04172.x

[42] Polo, S. and Di Fiore, P.P. (2008) Finding the Right Partner: Science or ART. Cell, 135, 590-592.

[43] Salghetti, S.E., Caudy, A.A., Chenoweth, J.G. and Tansey, J.W. (2001) Regulation of Transcriptional Activation Domain Function by Ubiquitin. Science, 293, 1651-1653. http://dx.doi.org/10.1126/science.1062079

[44] Rolland, F., Winderickx, J. and Thevelein, J.M. (2002) Glucose-Sensing and -Signalling Mechanisms in Yeast. FEMS Yeast Research, 2, 183-201. http://dx.doi.org/10.1111/j.1567-1364.2002.tb00084.x

[45] Santangelo, G.M. (2006) Glucose Signaling in Saccharomyces cerevisiae. Microbiology and Molecular Biology Reviews, 70, 253-282. http://dx.doi.org/10.1128/MMBR.70.1.253-282.2006

[46] Linhoff, M.W., Wright, K.L. and Ting, J.P. (1997) CCAAT-Binding Factor NF-Y and RFX Are Required for in Vivo Assembly of a Nucleoprotein Complex That Spans 250 Base Pairs: The Invariant Chain Promoter as a Model. Molecular and Cellular Biology, 17, 4589-4596.

[47] Flipphi, M., van de Vondervoort, P.J., Ruijter, G.J., Visser, J., Arst Jr., H.N. and Felenbok, B. (2003) Onset of Carbon Catabolite Repression in Aspergillus nidulans. Parallel Involvement of Hexokinase and Glucokinase in Sugar Signalling. The Journal of Biological Chemistry, 278, 11849-11857. http://dx.doi.org/10.1074/jbc.M209443200 
Scientific Research Publishing (SCIRP) is one of the largest Open Access journal publishers. It is currently publishing more than 200 open access, online, peer-reviewed journals covering a wide range of academic disciplines. SCIRP serves the worldwide academic communities and contributes to the progress and application of science with its publication.

Other selected journals from SCIRP are listed as below. Submit your manuscript to us via either submit@scirp.org or Online Submission Portal.
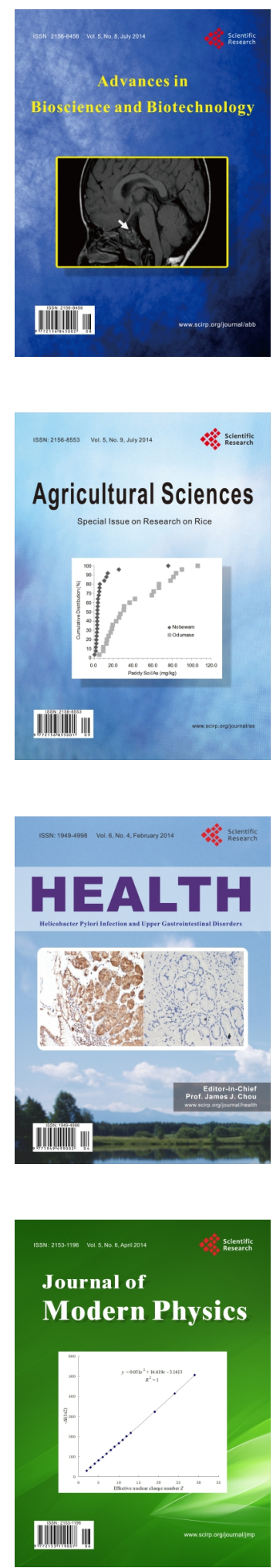
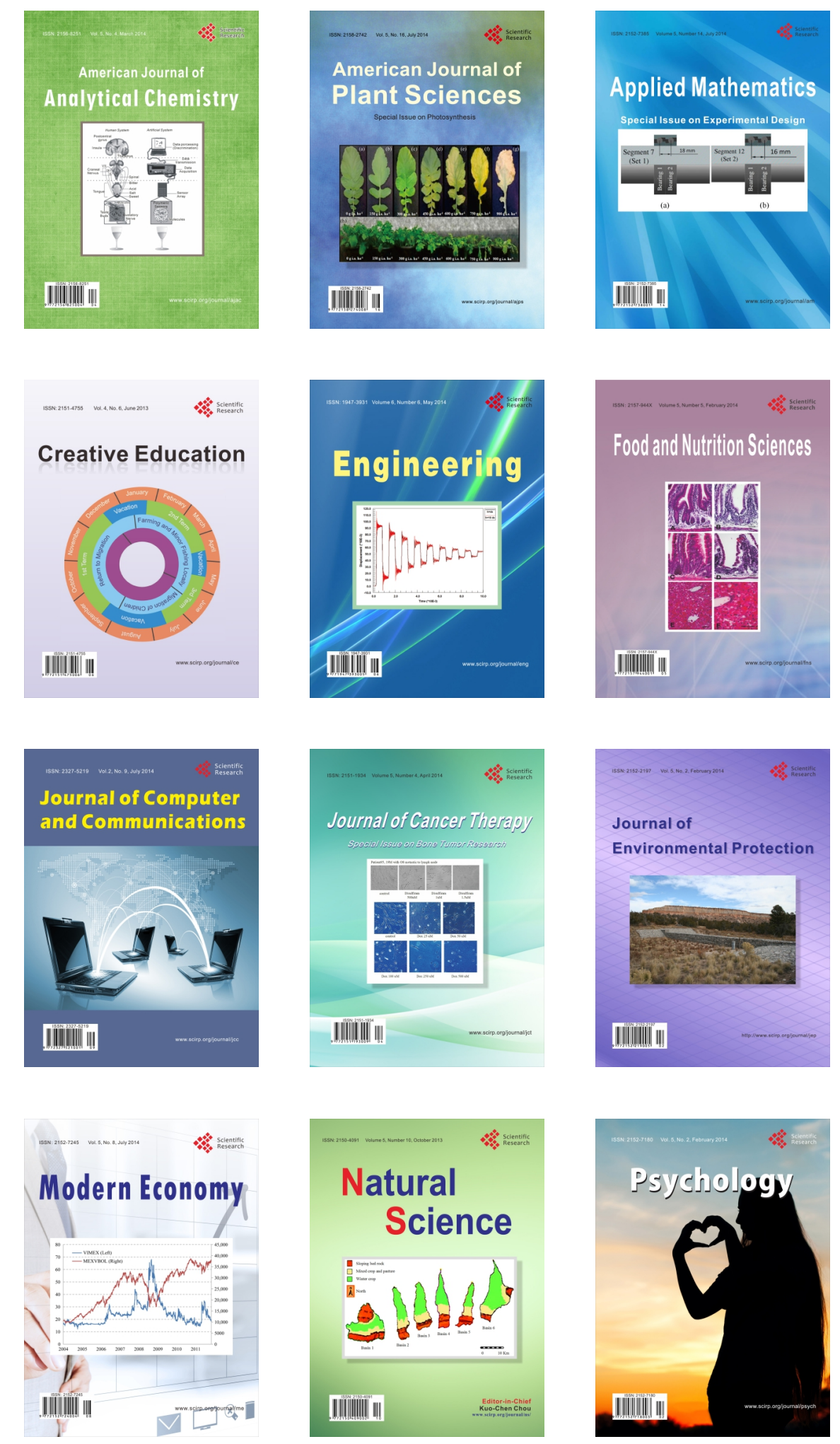